\title{
Energy Analysis and Efficiency Assessment of Water Tube Boiler
}

\author{
Trushar Patel (Assistant professor, MGITER-Navsari) \\ Divyesh Patel (Lecturer, Waghai -polytechnic )
}

\begin{abstract}
Energy is most precious thing, so it can be used most efficiency way. Most types of energy now a day's use in form of electricity, which is mainly generated in steam power plant and rest of source are wind, hydro and solar. The heart of steam power plant is boiler and to maximize efficiency of power plant, there is need to increase efficiency of boiler. The boiler efficiency can be evaluated by direct and indirect method, in direct method the energy gain by working fluid is compared with energy content of fuel while in case indirect method various losses compared to the energy input. Present work is concern on energy analysis and efficiency assessment of water tube boiler for sugar industry. By using catalyst what kind of effect on exhaust gas, combustion quality, environment friendliness, economy and up to what extent efficiency increase. By increasing boiler efficiency one can save fuel input to power plant and also earn carbon point and can increase profit to plant. From considering overall analysis and results it is concluded that, the pre boiler efficiency measured by $\mathrm{O}_{2}$ gas analyzer remains same as defined value without using solid combustion catalyst. It also shows that the efficiency of the pre-boiler leads to increase of the order of $2.82 \%, 2.86 \%$, $2.35 \%$ and $2.4 \%$ related to four different observed boilers with use of solid combustion catalyst, which is more supportive and required for the reduction of cost. The overall $2.61 \%$ improvement in the boiler efficiency as well as $3.3 \%$ reduction in baggase consumption. The overall saving of rupees 41, 19,000 with this efficiency is done after using the catalyst.
\end{abstract}

\section{Introduction}

Present time source of energy and its conservation and efficient production methods are researchable so present work focus on energy analysis and efficiency assessment of water tube boiler which is root cause of energy generation. The objective of trial at "shree Mahuva Pradesh S.K.U.M. Ltd, Mahuva" on their $2 \times 20$

TPH, $1 \times 25 \mathrm{TPH}$, and $1 \times 45$ TPH boilers Was establishing the efficiency of THERMACT-B by improving the boiler efficiency measured by $\mathrm{O}_{2}$ gas analyzer. The performance of water tube boiler is judge by THERMACTB solid combustion catalyst. In solid combustion catalyst test comparison of flue gas parameters of boiler using THERMACT-B.

\section{Performance assessment of boiler}

Pre trial test was conducted from $10^{\text {th }} \mathrm{Jan}$ ' 14 to $14^{\text {th }}$ Jan ' 14 for five days. The performance of boiler in pre-trial test was measuring required data like oxygen at APH outlet, carbon dioxide at APH outlet, carbon monoxide at APH outlet, excess air at APH outlet, APH outlet temperature and boiler efficiency by $\mathrm{O}_{2}$ gas analyzer.

Table 1: pre audit flue gas parameters

\begin{tabular}{|c|c|c|c|c|c|}
\hline Parameters of flue gas & Unit & Boiler 1 & Boiler 2 & Boiler 3 & Boiler 4 \\
\hline $\mathrm{O}_{2}$ at $\mathrm{APH}$ outlet & $\%$ & 12.66 & 11.03 & 8.82 & 9.30 \\
\hline $\mathrm{CO}_{2}$ at $\mathrm{APH}$ outlet & $\%$ & 754.15 & 783.95 & 996.1 & 1167.35 \\
\hline $\mathrm{CO}$ at $\mathrm{APH}$ outlet & $\mathrm{ppm}$ & 8.15 & 9.78 & 11.98 & 11.51 \\
\hline Excess air & $\%$ & 157.7 & 113.45 & 73.1 & 80.95 \\
\hline $\mathrm{APH}$ outlet temperature & ${ }^{\circ} \mathrm{C}$ & 150.95 & 144.2 & 149.0 & 129.65 \\
\hline Boiler efficiency & $\%$ & $\mathbf{5 9 . 0 1}$ & $\mathbf{6 1 . 2 6}$ & $\mathbf{6 1 . 5 1}$ & $\mathbf{6 2 . 4 2}$ \\
\hline
\end{tabular}

Post-trial was conducted from $20^{\text {th }}$ Jan ' 14 to $4^{\text {th }}$ Feb ' 14 for 15 days. The performance parameter of boiler in post-trial test was considering same as above pre-trial test.

Table 2: post audit flue gas parameters

\begin{tabular}{|c|c|c|c|c|c|}
\hline Parameters of flue gas & Unit & Boiler 1 & Boiler 2 & Boiler 3 & Boiler 4 \\
\hline $\mathrm{O}_{2}$ at $\mathrm{APH}$ outlet & $\%$ & 7.98 & 7.35 & 7.30 & 7.23 \\
\hline $\mathrm{CO}_{2}$ at $\mathrm{APH}$ outlet & $\%$ & 14.91 & 13.44 & 13.50 & 13.57 \\
\hline $\mathrm{CO}$ at APH outlet & $\mathrm{ppm}$ & 662.27 & 669.13 & 648.92 & 722.78 \\
\hline Excess air & $\%$ & 62.6 & 54.02 & 53.22 & 52.60 \\
\hline $\mathrm{APH}$ outlet temperature & ${ }^{\circ} \mathrm{C}$ & 149.0 & 144.7 & 147.68 & 130.65 \\
\hline Boiler efficiency & $\%$ & $\mathbf{6 0 . 6 7}$ & $\mathbf{6 3 . 0 1}$ & $\mathbf{6 2 . 9 6}$ & $\mathbf{6 3 . 9 2}$ \\
\hline
\end{tabular}

III. Thermact-B (solid combustion catalyst)

THERMACT-B additives, it works to counteract the effect of moisture in the bagasse fuel. Typically the moisture in bagasse absorbs heat from the bagasse combustion, losing heat both prior $100^{\circ} \mathrm{C}$ and further 
losing energy during the vapor phase (latest heat of vaporization). The THERMACT-B additive is a solid mixture of primarily carbon the helps breaking the bond between the two hydrogen and oxygen molecule. The additive essentially lowers the activation energy required for breaking the $\mathrm{H}-\mathrm{O}-\mathrm{H}$ bond. The THERMACT-B then increases the reactivity between the carbon and the moisture in bagasse. The first catalyst action creates $\mathrm{CO}_{2}$ and $\mathrm{H}_{2}$ from the $\mathrm{C}$ and $\mathrm{H}_{2} \mathrm{O}$, while the second catalyst reaction brings together the $\mathrm{C}$ and $\mathrm{H}_{2}$ to $\mathrm{create} \mathrm{CH}_{4}$, which is then destroyed to provide additional heat. The results is that amount of heat generated per unit of fuel increases, and thus less fuel is required to achieve the same level of heat output.

$$
\begin{aligned}
& \mathrm{C}+\mathrm{H}_{2} \mathrm{O} \\
& \mathrm{CO}+1 / 2 \mathrm{O}_{2} \\
& \mathrm{C}+2 \mathrm{H}_{2}
\end{aligned}
$$

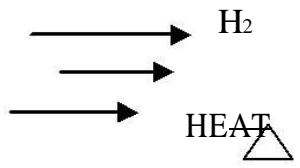

\section{VibroFeeder Assembly}

THERMACT-B is added directly in to the bagasse feeder. THERMACT-B was added directly into bagasse feeders with the help of Vibro-feeder assembly. The feed rate of THERMACT-B was controlled by the Vibro-feeder and regulator as per the bagasse consumption. $1 \mathrm{~kg}$ of THERMACT-B is dosed for 20 tons of bagasse.

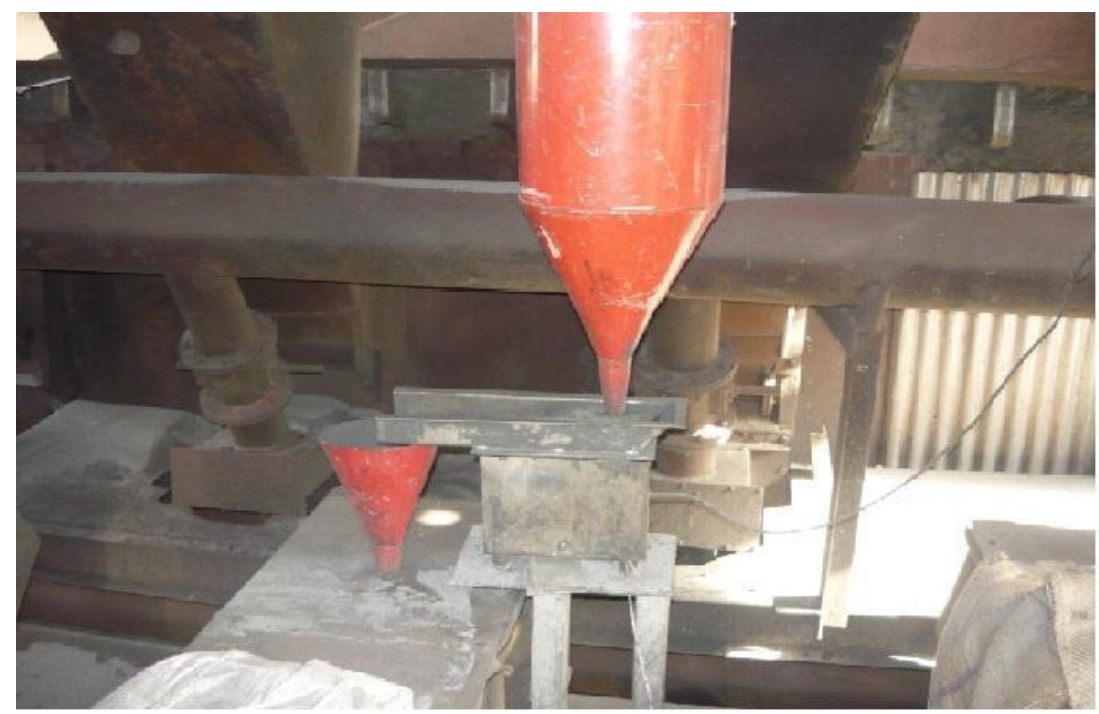

Figure 1:Vibrofeeder assembly

Table 3: Vibro-feeder assembly parameters

\begin{tabular}{|l|l|l|l|}
\hline Feed rate & $10 \mathrm{kgs} / \mathrm{hr}$ to $30 \mathrm{kgs} / \mathrm{hr}$ & Motor capacity & $0.5 \mathrm{HP}$ \\
\hline Screw RPM & 10 to 300 & Power supply & $220 \mathrm{~V} / 440 \mathrm{~V}, \mathrm{AC}, 50 \mathrm{HZ}$ \\
\hline Hopper capacity & $500 \mathrm{kgs}$ & Power consumption & $0.5 \mathrm{KW}$ \\
\hline Accuracy & $\pm 2.5 \%$ & & \\
\hline
\end{tabular}

\section{Comparison result of THERMACT-B}

THERMACT-B, solid combustion catalyst added in bagasse fuel. The effect of product after and before results shown below

Unburnt in fly ash

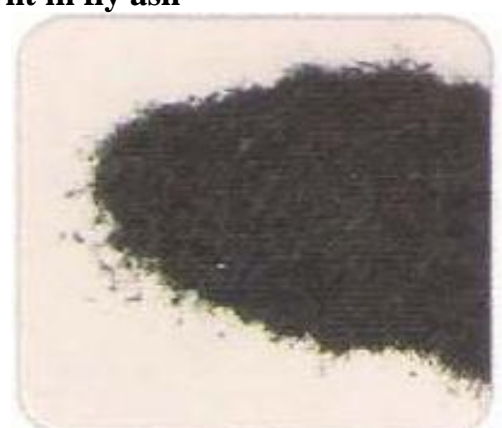

Figure 2 (a) Without THERMACT-B

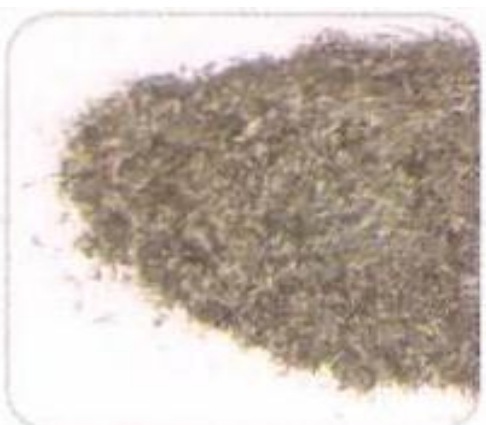

(b) With THERMACT-B 
$>$ from an incomplete combustion.

$>\quad$ The effect of with THERMACT-B fly ash and bottom ash is whitish indicating absence of unburned

carbons.

\section{Clinker formation}

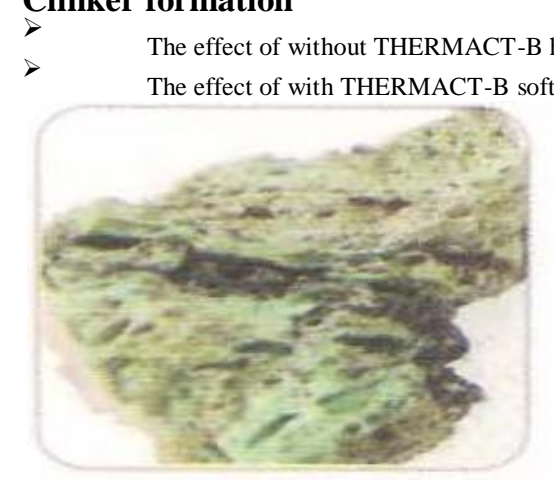

Figure 3 (a) Without THERMACT-B

Flame characteristics

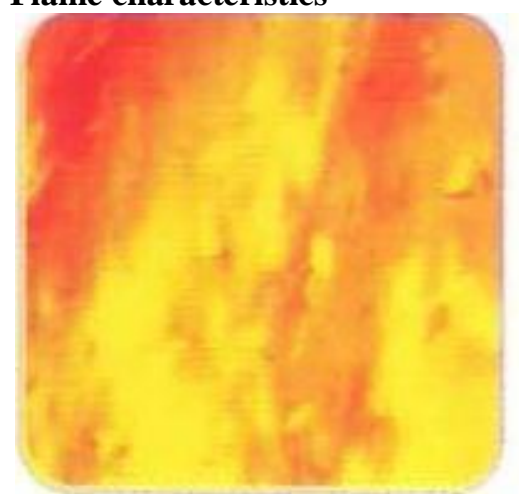

Figure 4 (a) Without THERMACT-B

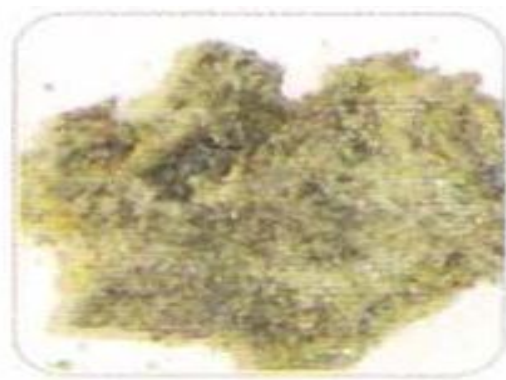

(b) With THERMACT-B

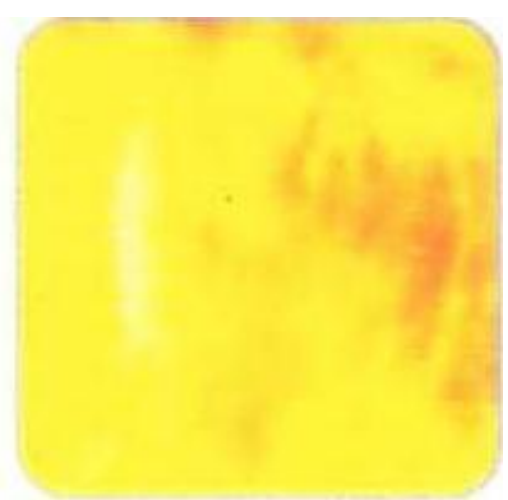

(b) With THERMACT-B combustion.

$>$ The effect of with THERMACT-B flame colors is bright orange/ yellow indicating higher flame temperature and more
complete combustion.

\section{Results and discussion}

Present work concern on increase boiler efficiency by studying various heat loosing activity during combustion process. Boiler efficiency can be reach as high as to pick point by minimizing the various heat losses. With reference of Mahuva sugar factory, there are four boilers mainly use bagasse as solid fuel. Considering energy audit data mainly heat loss occurs due to moisture content of bagasse only. By considering that fact, using catalyst efforts are make to reduce moisture content \& also due to catalyst reaction $\mathrm{CH}_{4}$ introduce in that process so addition heat produce within this process.

Table 4: Parameters of Flue Gas

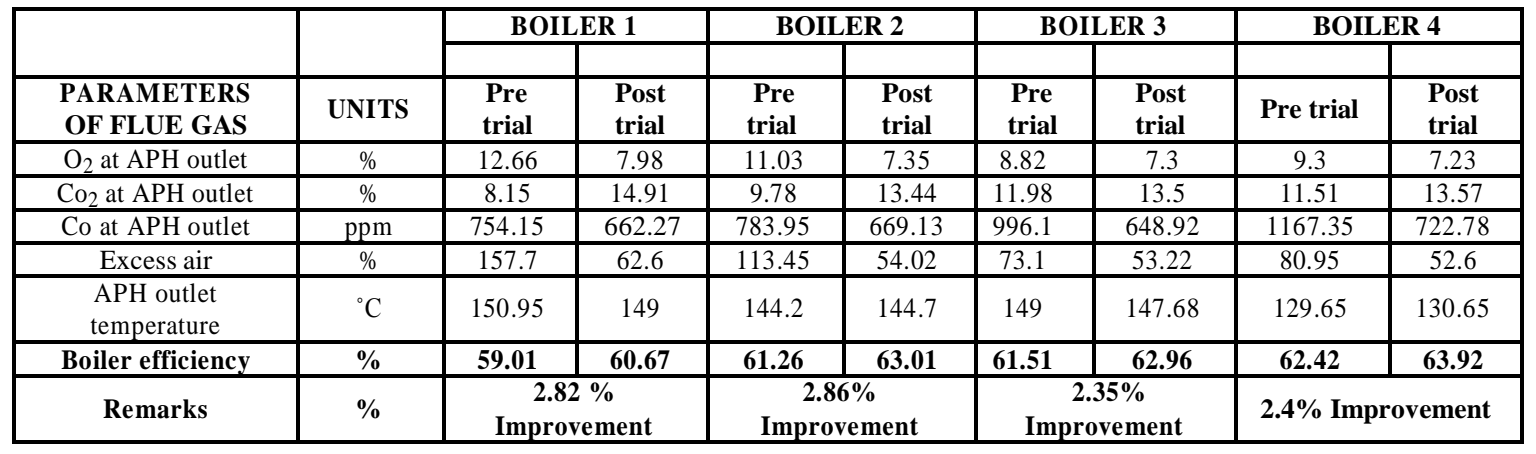




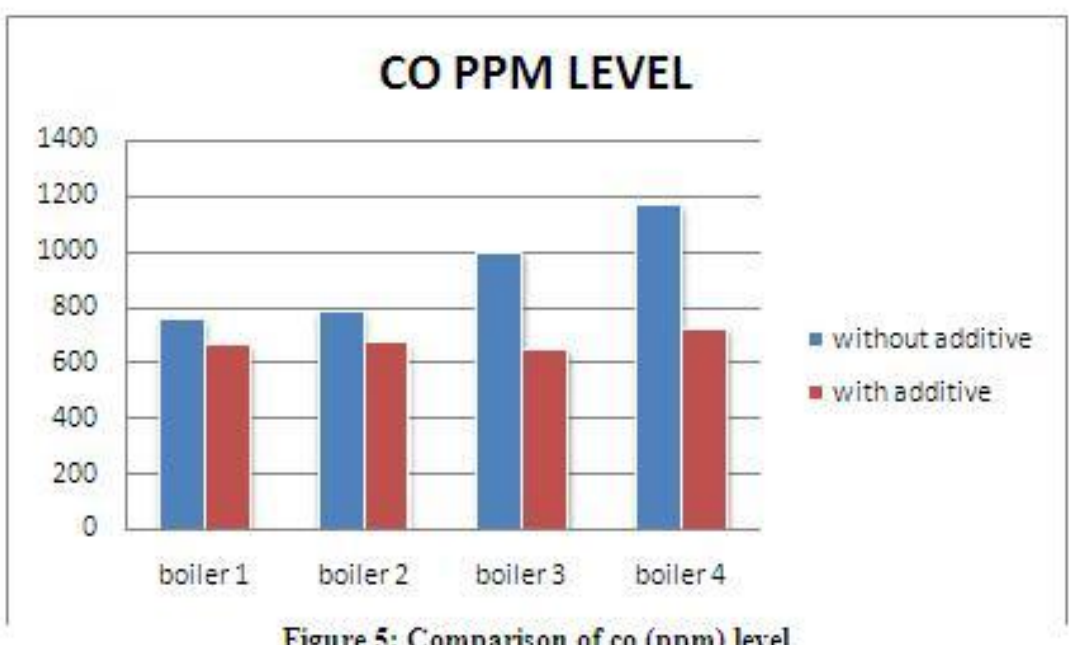

Figure 5: Comparison of co (ppm) level

Figure 5 shows that all boilers have tremendous reduction in CO PPM level due to catalyst reaction, in first catalyst reaction $\mathrm{H}_{2} \mathrm{O}$ reacts with $\mathrm{C}$ and make $\mathrm{CO}$ then after during second catalyst reaction $\mathrm{C}$ react with $\mathrm{H}_{2}$ and form $\mathrm{CH}_{4}$ mean while part of $\mathrm{CO}$ reacts with $1 / 2 \mathrm{O}_{2}$ and form $\mathrm{CO}_{2}$.

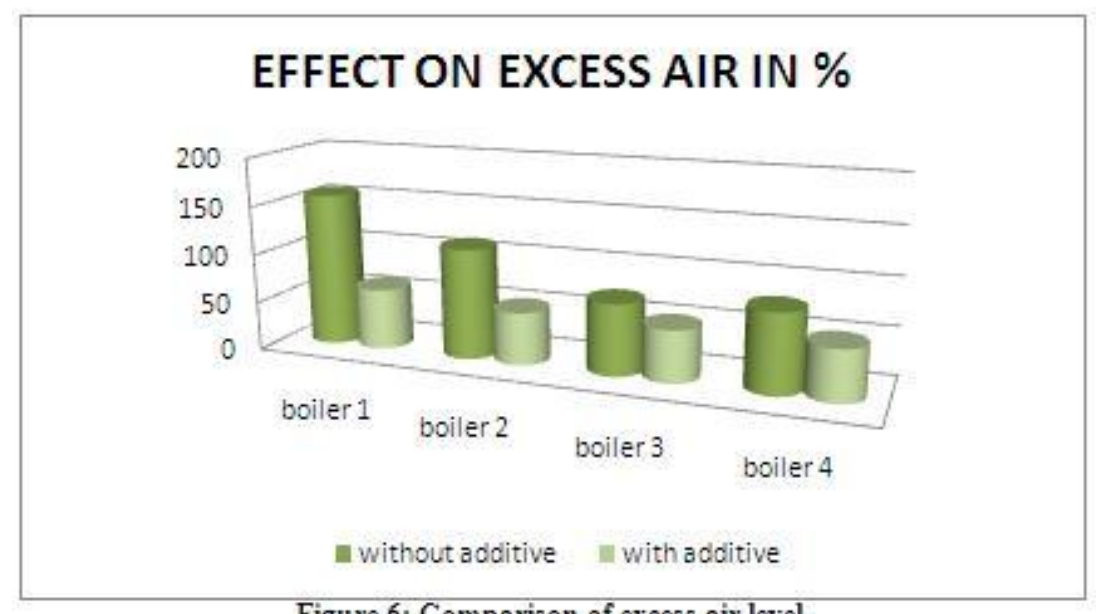

Figure 6: Comparison of excess air level

Figure 6 shows that with using additive there is great amount reduction in excess air in flue gases due to complete combustion of fuel.

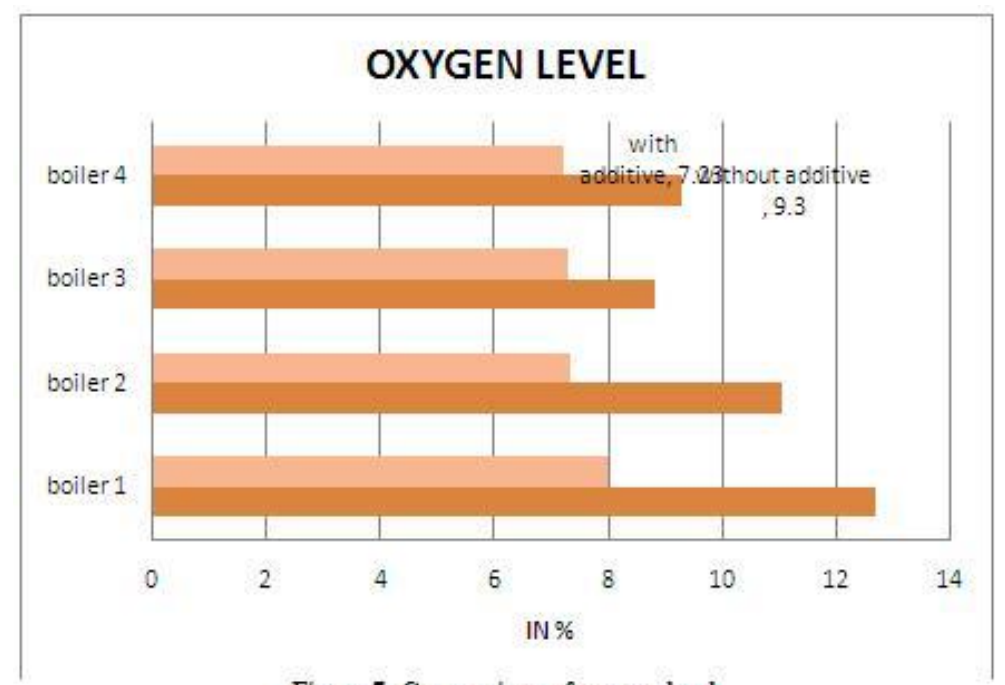

Figure 7: Comparison of oxygen level 
Figure 7depicts that due to complete combustion there is reduction in oxygen level in flue gases. Due to catalytic reaction maximum amount of $\mathrm{O}_{2}$ utilize in combustion process.

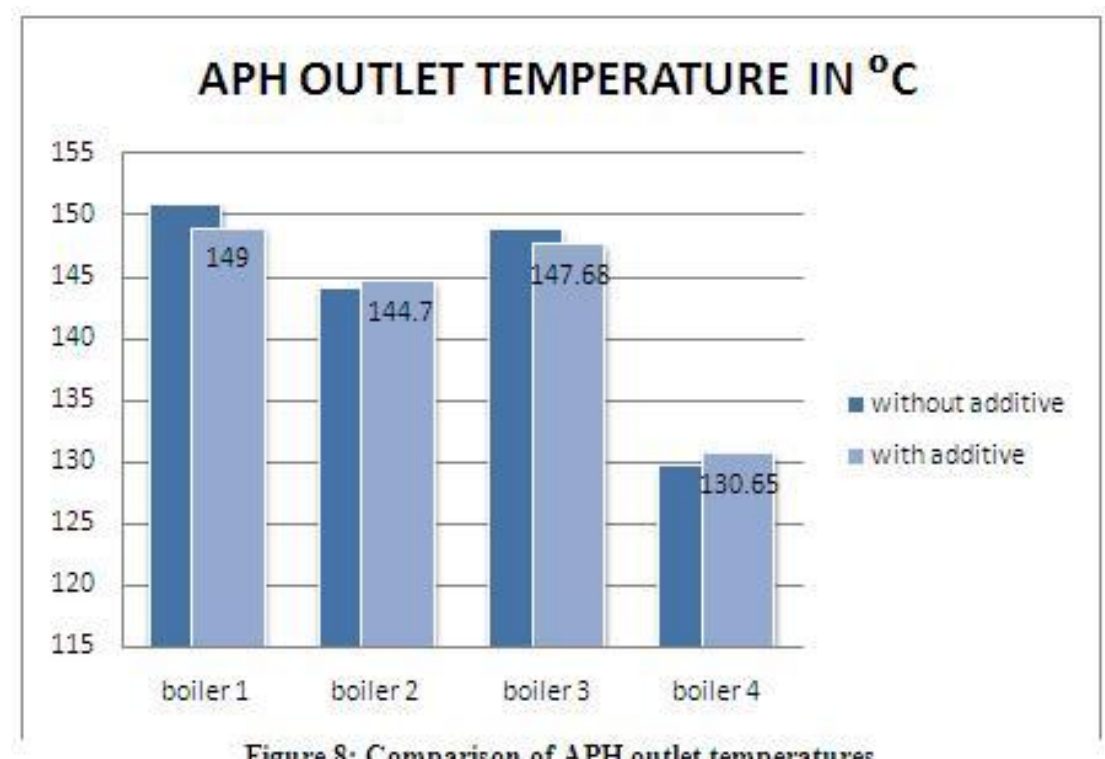

Figure 8: Comparis on of APH outlet temperatures

Figure 8 shows that there is minor temperature reduction at APH due to reduction in moisture content during combustion process, major amount of heat is carried by moisture and reduction of moisture ultimately results in reduction in temperature.

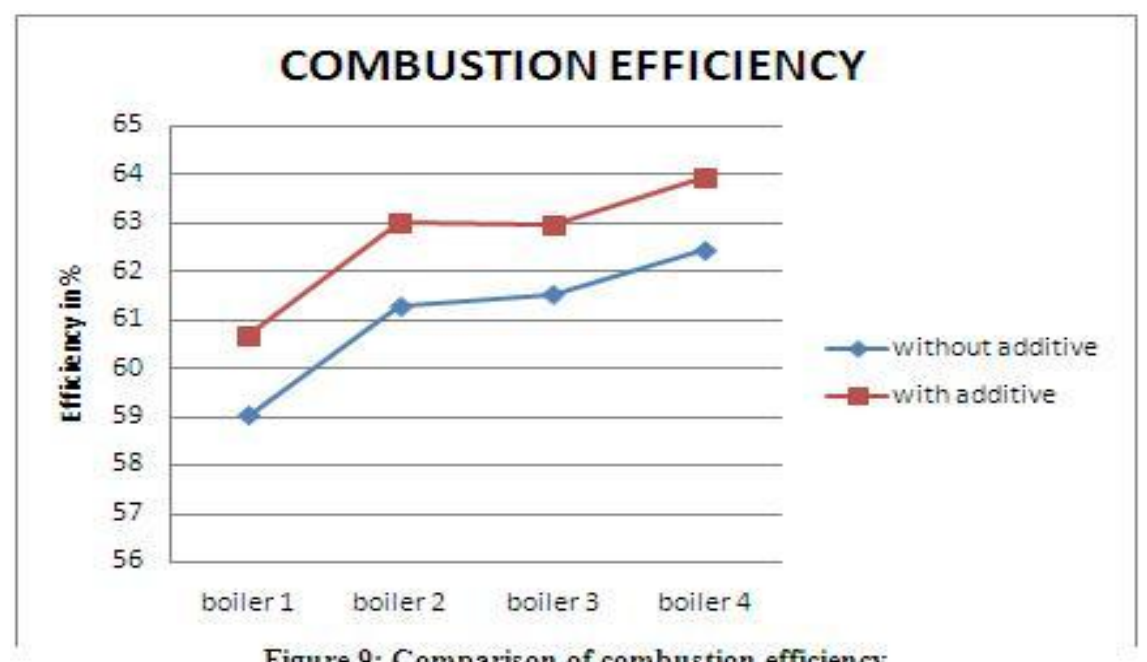

Figure 9: Comparison of combustion efficiency

Figure 9 shows that with the use of additive there are increasing in combustion efficiency due to reduction in heat loss activity and introducing $\mathrm{CH}_{4}$ which provides extra heat.

\section{Conclusion}

From considering overall analysis and results it is concluded that, the pre boiler efficiency measured by $\mathrm{O}_{2}$ gas analyzer remains same as defined value without using solid combustion catalyst. It also shows that the efficiency of the pre-boiler leads to increase of the order of $2.82 \%, 2.86 \%, 2.35 \%$ and $2.4 \%$ related to four different observed boilers with use of solid combustion catalyst, which is more supportive and required for the reduction of cost. The overall $2.61 \%$ improvement in the boiler efficiency as well as $3.3 \%$ reduction in baggase consumption. The overall saving of rupees $41,19,000$ with this efficiency is done after using the catalyst.

\section{References}

[1]. Saidur, R. (Year 2011) "Energy Savings and Emission Reductions in Industrial Boilers" Vol. 15, No. 3, pp. 705-719

[2]. Kumar Rayaprolu by boilers for power and process "CRC taylor and francis group"

[3]. Bureau of energy efficiency by Constituted by Energy Conservation Act, 2001 